\title{
Navigating work disability paradigms and reform in Canada
}

Emile Tompa

Institute for Work \& Health, Toronto M5G 2E9, Canada. etompa@iwh.on.ca

Objective: We investigate labour-market earnings of workers' compensation claimants from three distinctly different workers' compensation insurance support programs for claimants with permanent impairments. These three programs, which existed in Ontario, Canada in different periods over the last 25 years, are the Permanent Disability (PD) program, the Future Economic Loss (FEL) program, and the Loss of Earnings (LOE) program. The nature of benefit determination and the return to work supports provided by three programs are very different. The focus of the study is on evidence of programmatic impact on labour-market earnings recovery trajectories over nine years post injury.

Methods: The study included claimants sampled from each of the three programs who sustained a permanent impairment from a work injury. Claimants were identified in a Revenue Canada tax file database known as the Longitudinal Administrative Databank (LAD), which is a longitudinal 20\% simple random sample of all Canadian tax filers. Each claimant was matched with similar uninjured controls that were also in the LAD, based on sex, age, labour-market earnings amounts and trajectories in the four years prior to injury, and a propensity score. Statistical modeling analysis was undertaken to compare the labour-market earnings trajectories of claimants relative to their matched controls using data on earnings over the nine years post injury. Analyses focused on sub-strata defined by program, sex, age, permanent impairment level, and pre-injury earnings. A key issue of interest was to determine which program of supports resulted in the best labour-market earnings recovery.

Results: Five distinct earnings recovery trajectories were identified. Claimants in various demographic and preinjury earnings sub-strata from the LOE program cohort had a statistically significant lower probability of the lowest earnings recovery trajectory, and higher probability of the second highest trajectory compared to the PD cohort. Results for the LOE program were similar to the FEL program.

Conclusions: Injured workers from the LOE program appear to fare better than claimants from the PD program and similarly to those from the FEL program in terms of labour-market earnings recovery over the nine years post injury. Across all programs, older claimants fare more poorly, and women fare worse than men in terms of labour-market earnings recovery. 